\title{
Climate, traffic-related air pollutants and allergic rhinitis prevalence in middle-school children in Taiwan
}

\author{
Y-L. Lee*\#, , C-K. Shaw ${ }^{+}$, H-J. Su*, J-S. Lai ${ }^{\S}$, Y-C. Ko ${ }^{f}$, S-L. Huang**, F-C. Sung ${ }^{\# \#, ~ Y . L . ~ G u o *, \# ~}$
}

Climate, traffic-related air pollutants and allergic rhinitis prevalence in middle-school children in Taiwan. Y-L. Lee, C-K. Shaw, H-J. Su, J-S. Lai, Y-C. Ko, S-L. Huang, F-C. Sung, Y.L. Guo. (C) ERS Journals Ltd 2003.

ABSTRACT: The prevalence of allergic rhinitis, a common respiratory disorder, may be rapidly increasing. Epidemiological studies, however, indicate little about its association with climatic factors and air pollution. The relationship between trafficrelated air pollutants and allergic rhinitis in middle-school students was therefore investigated.

In a nationwide survey of middle-school students in Taiwan conducted in 1995/1996, the lifetime prevalence of physician-diagnosed allergic rhinitis and typical symptoms of allergic rhinitis were compared with air-monitoring station data on temperature, relative humidity, sulphur dioxide $\left(\mathrm{SO}_{2}\right)$, nitrogen oxides $(\mathrm{NOx})$, ozone $\left(\mathrm{O}_{3}\right)$, carbon monoxide $(\mathrm{CO})$ and particulate matter with a $50 \%$ cut-off aerodynamic diameter of $10 \mu \mathrm{m}$ (PM10).

A total of 331,686 nonsmoking children attended schools located within $2 \mathrm{~km}$ of 55 stations. Mean (range) annual exposures were: CO $853(381-1,610)$ parts per billion (ppb), NOx 35.1 (10.2-72.4) ppb, $\mathrm{SO}_{2} 7.57$ (0.88-21.2) ppb, PM10 69.2 (40.1-116.2) $\mu \mathrm{g} \cdot \mathrm{m}^{-3}, \mathrm{O}_{3} 21.3(12.4-34.1) \mathrm{ppb}$, temperature $22.9(19.6-25.1){ }^{\circ} \mathrm{C}$, and relative humidity $76.2(64.8-86.2) \%$. The prevalence of physician-diagnosed allergic rhinitis was 28.6 and $19.5 \%$ in males and females, respectively, with prevalence of questionnaire-determined allergic rhinitis $\mathbf{4 2 . 4}$ and $\mathbf{3 4 . 0} \%$. After adjustment for age, parental education and history of atopic eczema, physician-diagnosed allergic rhinitis was found to be associated with higher nonsummer (September-May) warmth and traffic-related air pollutants, including $\mathrm{CO}, \mathrm{NOx}$ and $\mathrm{O}_{3}$. Questionnaire-determined allergic rhinitis correlated only with traffic-related air pollutants.

Nonsummer warmth and traffic-related air pollution, probably mediated through exposure to common allergens such as dust mites, are possible risk factors for allergic rhinitis in middle-school-aged children.

Eur Respir J 2003; 21: 964-970.
Depts of *Environmental and Occupational Health and ${ }^{\#}$ Internal Medicine, "Institute of Basic Medical Sciences, National Cheng Kung University, Tainan, ${ }^{+}$Dept of Public Health, Tzu-Chi University, Hua-lien, ${ }^{\S}$ Dept of Occupational Safety and Health, China Medical College, Taichung, ${ }^{f}$ Dept of Public Health, Kaohsiung Medical University, Kaohsiung, **Institute of Environmental Health Sciences,

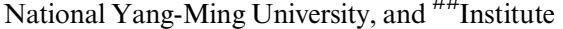
of Environmental Health, National Taiwan University, Taipei, Taiwan.

Correspondence: Y. L. Guo, Dept of Environmental and Occupational Health, National Cheng Kung University, 138 Sheng-Li Road, Tainan 704, Taiwan.

Fax: 88662743748

E-mail: leonguo@mail.ncku.edu.tw

Keywords: Air pollution, allergic rhinitis, children, climate, factor analysis

Received: October 162002

Accepted after revision: January 92003

This study was funded by grant No. 88-EPAZ006-018 from the Environmental Protection Administration and grant No. NSC-87-2621P-006-013 from the National Science Council (both Taipei, Taiwan).
Allergic rhinitis, especially in adolescents and children, has become a major public-health problem in developed and developing countries [1]. According to the Tucson Children's Respiratory Study [2], for example, during 1986-1990, the prevalence of physician-diagnosed allergic rhinitis was estimated at $42 \%$ in children during their first 6 yrs of life. In 1993, self-diagnosed allergic rhinitis was reported as $14.2 \%$ in the USA, ranging $11.7-20.2 \%$ in different regions [3], but, considering all possible associated symptoms, the prevalence was $31.5 \%$. In addition, considerable evidence has been presented about increasing prevalences of atopic diseases, such as asthma, allergic rhinitis and atopic eczema [4, 5]. A large-scale cohort study in the UK revealed a rising trend of allergic rhinitis, from 12 to $23 \%$ during 1958-1970 [6]. Several large surveys in Switzerland also showed increasing prevalence of self-reported hay fever from $9.6 \%$ in 1985 to $13.5 \%$ in 1992 [7]. Similar results have also been reported all around the world $[2,8,9]$.

Except for age [10], family history with genetic risks [2, 11], and family size or number of siblings [12], there seem to be no reliable predictors of allergic rhinitis. The results of epidemiological studies investigating the relation between air pollution

For editorial comments see page 913. and allergic rhinitis are also contradictory. Preliminary studies from Germany [13, 14] and Italy [15] suggested a positive correlation between traffic density and the morbidity of allergic rhinitis. Ambient air-pollution level was also noted to be associated with the prevalence [16-19] and severity of allergic rhinitis [20]. In contrast to these results, a series of other epidemiological studies found no significant association between traffic-related air pollution and allergic rhinitis $[9,11$, $21,22]$, although several reports demonstrated traffic-related motor vehicle exhaust fumes could interact with pollen grains or allergen-bearing particles, and may increase their allergenicity $[13,14,16]$.

Low temperatures may have a direct effect on exacerbations of asthma symptoms in the short term [23, 24]; however, warmer mean temperatures contrarily revealed an association with increased asthma prevalence [18, 25], although, for allergic rhinitis, relevant report was limited in scope. A recent study in Italy showed a higher climate indicator, including higher mean temperature and lower temperature range, in the Mediterranean region was associated with asthma symptoms, but not with the prevalence of allergic rhinitis [16]. Furthermore, climate was also proven as a modifier of the association between traffic pollution, and could increase the risk for 
allergic rhinitis in those exposed to stable, higher temperatures [16].

The present study was designed to compare allergic rhinitis prevalences from a nationwide survey of air pollution and climatic data. The relationship between traffic-related air pollutants, climatic factors and allergic rhinitis in middleschool students in Taiwan is described.

\section{Materials and methods}

\section{Design and study methods}

A nationwide survey of respiratory diseases and symptoms in middle-school students in Taiwan was conducted between October 1995 - May 1996. A total of 800 middle schools in 24 counties and cities were investigated. The study protocol was approved by the Respiratory Health Screening Steering Committee of Taiwan Environmental Protection Administration (Taipei, Taiwan) and the Institutional Review Board at National Cheng Kung University Medical College (Tainan, Taiwan), and complied with the principles outlined in the Helsinki Declaration [26]. The standard International Study of Asthma and Allergies in Childhood, Chinese version, questionnaire was taken home by students and answered by parents. Only some personal data, such as smoking or drinking habits were reported by the children themselves. Subjects were mostly aged 12-14 yrs.

\section{Definition of allergic rhinitis}

Two indicators of allergic rhinitis were considered. Physiciandiagnosed allergic rhinitis was defined by parental report in answer to the question "Have you ever being diagnosed as having allergic rhinitis by a physician?" Information on questionnaire-determined symptoms of allergic rhinitis was obtained with the question "Have you ever had a problem with sneezing, or a runny or blocked nose, when you did not have a cold or the flu?" Atopic eczema was defined as the presence of itching skin eruptions at the cubital, popliteal, neck, periauricular and eyebrow areas for $\geqslant 6$ months, or the diagnosis of atopic eczema by a physician in the subject's history. Information on lifetime prevalences of allergic rhinitis and atopic eczema were obtained using these definitions.

\section{Air pollution and meteorological data}

Complete monitoring data for the air pollutants sulphur dioxide $\left(\mathrm{SO}_{2}\right)$, nitrogen oxides $(\mathrm{NOx})$, ozone $\left(\mathrm{O}_{3}\right)$, carbon monoxide (CO) and particulate matter with a $50 \%$ cut-off aerodynamic diameter of $10 \mu \mathrm{m}$ (PM10), as well as daily temperature and relative humidity, were available from 66 Environmental Protection Administration monitoring stations from 1994. Concentrations of each pollutant were measured continuously, $\mathrm{CO}$ by nondispersive infra-red absorption, NOx by chemiluminescence, $\mathrm{O}_{3}$ by ultraviolet absorption, $\mathrm{SO}_{2}$ by ultraviolet fluorescence and PM10 by beta gauge, and reported hourly. The study population was limited to children attending schools located within $2 \mathrm{~km}$ of 55 of these monitoring stations; 11 stations were discarded because there were no schools in the $2-\mathrm{km}$ catchment areas.

Community-specific annual means for each air pollutant, temperature and relative humidity, in 1994, were calculated as the mean of the 1994 monthly means. Temperature and relative humidity were highly correlated across the communities, and there were also strong between-site correlations of the five monitored air pollutants. Principal component factor analysis with varimax rotation [27] was used to produce independent indicators of the community-specific climate and source-specific indicators of exposure to air pollution.

\section{Statistical analysis}

Previously reported analyses of respiratory health outcomes have demonstrated a larger intercity variation than would be predicted by interindividual variation $[22,28]$. Twostage methods were used to correct for any excess betweensite variability. In the first step, a logistic regression model was used to estimate the adjusted logit of sex-specific disease frequency in each of the 55 catchment areas, controlling for the known individual-level confounders, such as age, parental education and history of atopic eczema, whose differential distributions in communities were associated independently with air pollution. Self-reported active smokers were excluded. In the second step, these community-specific adjusted logits of allergic rhinitis were regressed against the community-specific temperature, relative humidity and air-pollution factors; the regression used weights inversely proportional to the sum of the between-site and within-site variances of the adjusted logits. Results from the second step were summarised as odds ratios (ORs) in order to determine the relative effectiveness for each factor score of temperature, relative humidity and air pollutants on the prevalence of allergic rhinitis. The sexspecific adjusted prevalences of allergic rhinitis were plotted against the scores of rotated components of traffic-related air pollutants. Significance was set at $\mathrm{p}<0.05$.

\section{Results}

In 1995, 1,139,452 students were enrolled in 800 middle schools in 24 counties and cities in Taiwan. A total of $1,018,031(89.3 \%)$ students and their parents responded to the questionnaire satisfactorily (individual school range 87-93\%). Of that number, $332,686(32.7 \%$; 161,744 males, 170,942 females) were nonsmokers and enrolled in a school within the $2-\mathrm{km}$ catchment areas of each air monitoring station. After excluding questionnaires with unanswered questions, data from 312,873 (30.1\%; 153,602 males, 159,271 females) remained for further analysis. Table 1 shows the characteristics of study subjects by sex, and ORs for risk factors by multiple logistic regression model. Prevalences of physician-diagnosed allergic rhinitis were 28.6 and $19.5 \%$ in males and females, respectively, with prevalences of questionnaire-determined allergic rhinitis of 42.4 and $34.0 \%$.

Table 2 summarises the community-specific air pollution and meteorological annual means. Two factors were identified from principal component analysis of community-specific temperature: nonsummer warmth, and summer warmth (table 3); three factors were found for relative humidity: summer and autumn humidity, spring dryness, and winter humidity. Two factors were identified for community-specific air pollutants (table 4). The first community-specific factor was positively associated with $\mathrm{CO}$ and $\mathrm{NOx}$ levels and negatively associated with $\mathrm{O}_{3}$ levels, suggesting traffic-related motor vehicle emissions; the second was highly associated with $\mathrm{SO}_{2}$ and PM10 levels, indicating emissions from power plants, industry and domestic fossil-fuel combustion, as previously reviewed for Taiwan [29].

Sex-specific adjusted logits of physician-diagnosed and questionnaire-determined allergic rhinitis were regressed against the two temperature factors, three relative humidity factors and two air pollutant factors, which were all normalised to scores with mean 0 and variance 1 . When climatic and air-pollutant factors were mutually adjusted, traffic-related 


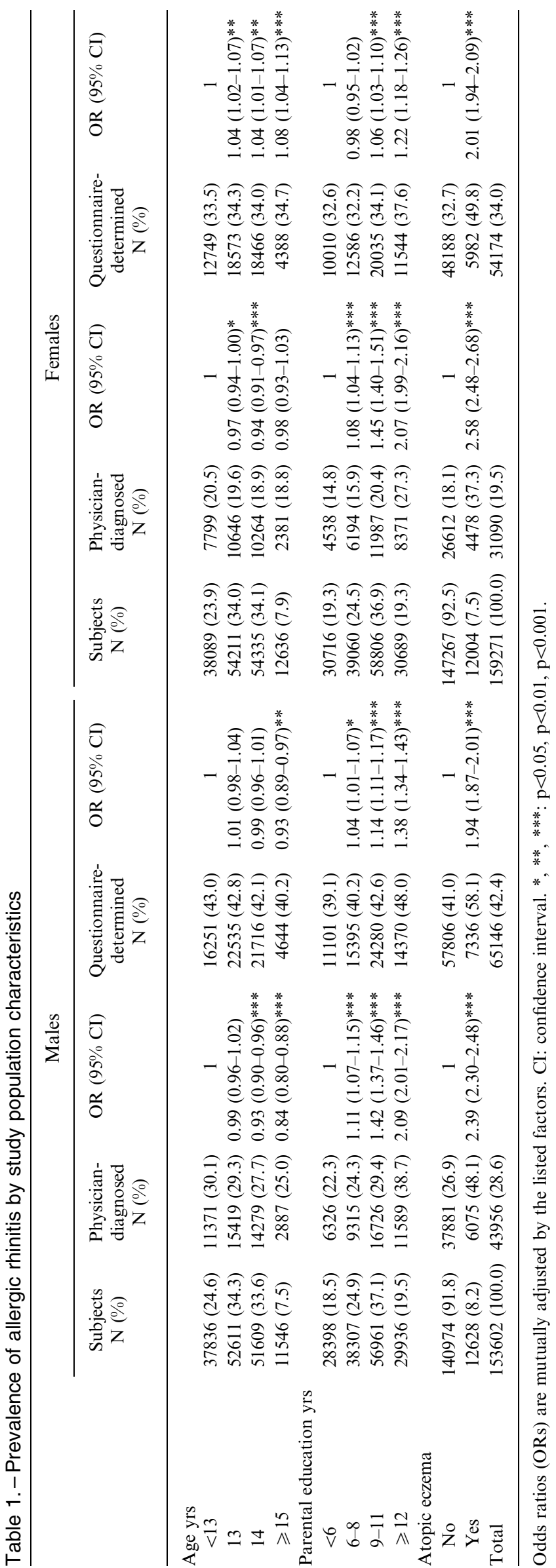

Table 2.-Annual air pollution and meteorological data for 1994 from 55 air-monitoring stations in Taiwan

\begin{tabular}{lcccc}
\hline & Mean \pm SD & Median & Range & IQR \\
\hline $\mathrm{CO}$ ppb & $853 \pm 277$ & 843 & $381-1610$ & $675-1001$ \\
$\mathrm{NOx} \mathrm{ppb}$ & $35.1 \pm 13.4$ & 34.0 & $10.2-72.4$ & $25.6-42.9$ \\
$\mathrm{SO}_{2} \mathrm{ppb}$ & $7.57 \pm 4.15$ & 7.22 & $0.88-21.2$ & $5.01-8.77$ \\
$\mathrm{PM} 10 \mu \mathrm{g} \cdot \mathrm{m}^{-3}$ & $69.2 \pm 17.8$ & 65.9 & $40.1-116.2$ & $54.0-81.7$ \\
$\mathrm{O}_{3} \mathrm{ppb}$ & $21.3 \pm 4.5$ & 21.5 & $12.4-34.1$ & $18.7-23.4$ \\
Temperature ${ }^{\circ} \mathrm{C}$ & $22.9 \pm 1.1$ & 22.8 & $19.6-25.1$ & $22.3-23.6$ \\
Relative humidity $\%$ & $76.2 \pm 3.7$ & 76.6 & $64.8-86.2$ & $74.8-78.6$ \\
\hline
\end{tabular}

IQR: interquartile range; $\mathrm{CO}$ : carbon monoxide; ppb: parts per billion; NOx: nitrogen oxides; $\mathrm{SO}_{2}$ : sulphur dioxide; PM10: particulate matter with a $50 \%$ cut-off aerodynamic diameter of $10 \mu \mathrm{m} ; \mathrm{O}_{3}$ : ozone.

air pollutants remained the main determinant of physiciandiagnosed allergic rhinitis (OR1.17, 95\% confidence interval (CI) $1.07-1.29$ in males; OR 1.16 , 95\% CI $1.05-1.29$ in females) (table 5); higher nonsummer (September-May) temperature was also positively related to prevalence of allergic rhinitis (OR 1.10, 95\% CI 1.02-1.19 in males; OR $1.09,95 \%$ CI $1.01-1.19$ in females). However, questionnairedetermined allergic rhinitis was associated only with trafficrelated air pollutants in both sexes. Interaction terms for temperature and humidity factors were used in the regression models and found to be nonsignificant (data not shown). Adjusted community-specific allergic rhinitis prevalences were plotted against traffic-related air-pollution factor scores (fig. 1). There were no obvious outliers. Quadratic and cubic terms were used in the regression models and these terms were also not significant (data not shown), which indicated the regression lines were compatible with linearity. In addition, a 1SD increase in traffic-related air-pollutant factor score represented an increase in CO level of 257 parts per billion (ppb) and in NOx level of $12.2 \mathrm{ppb}$ and a decrease in $\mathrm{O}_{3}$ level of $4.1 \mathrm{ppb}$.

After adjustment for climatic factors, the effects of each pollutant on physician-diagnosed and questionnaire-determined allergic rhinitis were assessed separately. In the regression model in which $\mathrm{p}$-values were calculated, significant associations were found for $\mathrm{CO}, \mathrm{NOx}$, and $\mathrm{O}_{3}$ levels in both sexes but none for $\mathrm{SO}_{2}$ and PM10 levels (data not shown). Negative and relatively weak correlations for $\mathrm{O}_{3}$ levels were also noted.

\section{Discussion}

The present study was based on a large data set and investigated the chronic effects of ambient air pollutants on allergic rhinitis in a cross-sectional design. The main results of the analysis showed that prevalences of both physiciandiagnosed and questionnaire-determined allergic rhinitis, occurring more frequently than other respiratory symptoms $[1,5,6,11]$, in middle-school students from 55 communities in Taiwan were associated with traffic-related air pollutants, especially NOx and CO.

Younger subjects and males showed a higher rate of reporting allergic rhinitis (table 1), as seen in other studies [9, 30-32]. It was also found that the level of parental education was associated with the occurrence of allergic rhinitis in children. Parents with a higher educational level were more likely to be aware of the specific health condition of their children. Moreover, the level of exposure to allergens was lower at higher socioeconomic levels, which would result in a protective effect in their children and make them more susceptible to specific allergens in older age [33, 34]. Since age, history of atopy and parental education were potential predictive factors for allergic rhinitis, these factors were 
Table 3. - Factor loading of monthly mean temperature and relative humidity in Taiwan, 1994

\begin{tabular}{|c|c|c|c|c|c|}
\hline & \multicolumn{2}{|c|}{ Temperature } & \multicolumn{3}{|c|}{ Relative humidity } \\
\hline & Factor 1 & Factor 2 & Factor 1 & Factor 2 & Factor 3 \\
\hline Eigenvalue ( $\%$ variance) & $9.27(77.3)$ & $1.67(14.0)$ & $5.62(46.8)$ & $2.14(17.8)$ & $1.35(11.2)$ \\
\hline \multicolumn{6}{|l|}{ Factor loading } \\
\hline January & 0.927 & 0.303 & 0.162 & -0.016 & 0.903 \\
\hline February & 0.929 & 0.283 & 0.160 & -0.242 & 0.902 \\
\hline March & 0.966 & 0.188 & 0.174 & -0.566 & 0.704 \\
\hline April & 0.896 & 0.235 & 0.122 & -0.809 & 0.188 \\
\hline May & 0.891 & 0.309 & 0.063 & -0.909 & 0.139 \\
\hline June & 0.398 & 0.856 & 0.209 & -0.737 & 0.077 \\
\hline July & 0.338 & 0.900 & 0.745 & -0.331 & 0.200 \\
\hline August & 0.082 & 0.901 & 0.746 & -0.366 & 0.076 \\
\hline September & 0.523 & 0.804 & 0.902 & -0.239 & 0.095 \\
\hline October & 0.747 & 0.587 & 0.875 & -0.122 & 0.134 \\
\hline November & 0.880 & 0.434 & 0.804 & -0.048 & 0.206 \\
\hline December & 0.867 & 0.413 & 0.733 & 0.110 & 0.046 \\
\hline Factor & Nonsummer warmth & Summer warmth & Summer/autumn humidity & Spring dryness & Winter humidity \\
\hline
\end{tabular}

Two factors have eigenvalues of $>1$ for temperature and account for $91.3 \%$ of variance; three have eigenvalues of $>1$ for relative humidity and account for $75.9 \%$ of variance.

Table 4. - Factor loading of mean annual levels of criteria air pollutants in Taiwan, 1994

\begin{tabular}{lcc}
\hline & Factor 1 & Factor 2 \\
\hline $\begin{array}{l}\text { Eigenvalue (\% } \\
\text { variance) }\end{array}$ & $2.92(58.3)$ & $1.31(26.2)$ \\
Factor loading & & \\
$\mathrm{CO}$ & 0.927 & 0.127 \\
$\mathrm{NOx}$ & 0.911 & 0.278 \\
$\mathrm{O}_{3}$ & -0.921 & 0.038 \\
$\mathrm{SO}_{2}$ & 0.268 & 0.827 \\
$\mathrm{PM}_{10}$ & -0.037 & 0.901 \\
Factor & Traffic-related & Fossil fuel \\
& & combustion related
\end{tabular}

Two factors have eigenvalues of $>1$ and account for $84.5 \%$ of variance. $\mathrm{CO}$ : carbon monoxide; NOx: nitrogen oxides; $\mathrm{O}_{3}$ : ozone; $\mathrm{SO}_{2}$ : sulphur dioxide; PM10: particulate matter with a 50\% cut-off aerodynamic diameter of $10 \mu \mathrm{m}$.

analysed in the first-stage regression. The questionnaire also enquired about other personal factors, such as daily cigarette consumption in families, incense burning at home and regular exercise. It was decided not to include these factors in the adjustment step for three reasons. First, cigarette smoking and incense use might be reduced by a family with a child with allergic rhinitis. The present results showed a negative association between these factors and allergic rhinitis (data not shown), which was consistent with recent studies in Sweden and Spain $[35,36]$. Secondly, the child could have been encouraged to exercise when exhibiting signs and symptoms of allergic rhinitis. Thirdly, inclusion of these factors might have given significant associations, but they would have been difficult to interpret for causality.

In children with a physician's diagnosis of allergic rhinitis, $80.9 \%$ were reported as having typical symptoms, whereas, in those without such a diagnosis, only $24.4 \%$ reported such symptoms $(\mathrm{p}<0.001)$. Underdiagnosis was possible in children with symptoms. In children diagnosed as having allergic rhinitis but without symptoms, it was likely that they were in remission or that their symptoms were transient and not recalled by the parents. According to the present definition, questionnaire-determined allergic rhinitis included a physician's diagnosis because it was thought it would be based on clinical symptoms, although some were possibly under-reported associated symptoms.

Table 5. - Relationship between physician-diagnosed and questionnaire-determined allergic rhinitis and environmental factors in middle-school students

\begin{tabular}{|c|c|c|c|c|c|c|c|c|}
\hline & \multicolumn{4}{|c|}{ Males } & \multicolumn{4}{|c|}{ Females } \\
\hline & \multicolumn{2}{|c|}{ Physician-diagnosed } & \multicolumn{2}{|c|}{ Questionnaire-determined } & \multicolumn{2}{|c|}{ Physician-diagnosed } & \multicolumn{2}{|c|}{ Questionnaire-determined } \\
\hline & OR & aOR $(95 \% \mathrm{CI})$ & OR & aOR $(95 \% \mathrm{CI})$ & OR & aOR $(95 \% \mathrm{CI})$ & OR & aOR $(95 \% \mathrm{CI})$ \\
\hline \multicolumn{9}{|l|}{ Air pollution } \\
\hline Traffic-related & $1.14 * *$ & $1.17(1.07-1.29)^{* *}$ & $1.07 *$ & $1.09(1.01-1.17)^{*}$ & $1.14 * *$ & $1.16(1.05-1.29)^{* *}$ & $1.10^{* *}$ & $1.12(1.04-1.20)^{* *}$ \\
\hline $\begin{array}{l}\text { Fossil fuel } \\
\text { combustion related }\end{array}$ & 1.05 & $1.00(0.92-1.08)$ & 1.02 & $1.00(0.94-1.06)$ & 1.05 & $0.99(0.90-1.08)$ & 1.01 & $0.99(0.93-1.05)$ \\
\hline \multicolumn{9}{|l|}{ Temperature } \\
\hline Nonsummer warmth & 1.02 & $1.10(1.02-1.19)^{*}$ & 1.01 & $1.05(0.99-1.11)$ & 1.02 & $1.09(1.01-1.19)^{*}$ & 1.00 & $1.04(0.98-1.11)$ \\
\hline Summer warmth & $1.11^{* *}$ & $1.00(0.91-1.10)$ & $1.07 *$ & $1.03(0.95-1.10)$ & $1.13^{* *}$ & $1.03(0.93-1.14)$ & $1.08^{*}$ & $1.02(0.95-1.09)$ \\
\hline \multicolumn{9}{|l|}{ Humidity } \\
\hline Summer/autumn & 0.97 & $0.99(0.93-1.06)$ & 1.00 & $1.03(0.98-1.08)$ & 0.98 & $1.01(0.94-1.09)$ & 0.98 & $1.02(0.97-1.08)$ \\
\hline Spring dryness & 0.94 & $0.95(0.89-1.02)$ & 0.98 & $0.99(0.94-1.04)$ & 0.95 & $0.97(0.90-1.04)$ & 0.98 & $1.00(0.95-1.05)$ \\
\hline Winter & 0.96 & $0.95(0.89-1.01)$ & 1.00 & $0.99(0.95-1.04)$ & 0.97 & $0.95(0.89-1.02)$ & 1.01 & $1.00(0.95-1.04)$ \\
\hline
\end{tabular}

Odds ratios (ORs) are expressed for a change in each factor by $1 \mathrm{SD}$. aOR: mutually adjusted $\mathrm{OR}$; CI: confidence interval. $*, * *$ p $<0.05, \mathrm{p}<0.01$. 

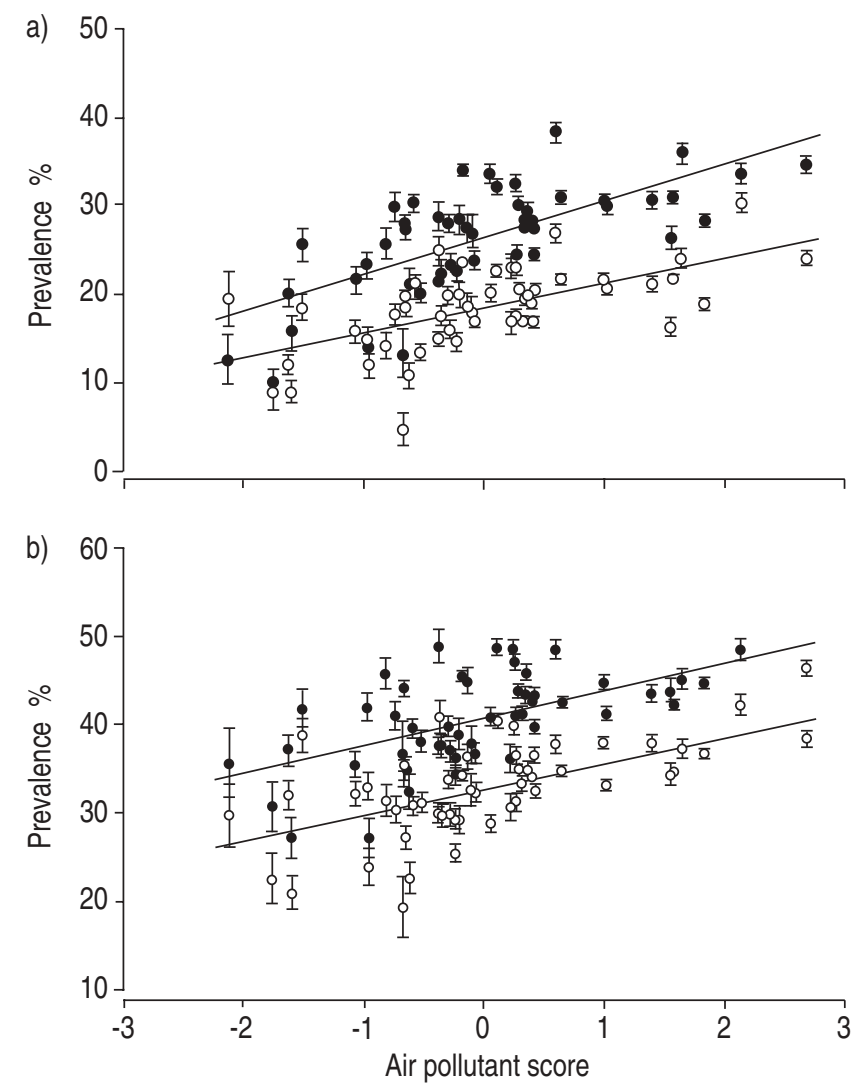

Fig. 1.-Association of traffic-related air pollutant scores with prevalence of: a) physician-diagnosed and b) questionnaire-determined allergic rhinitis adjusted for age, atopic eczema and parental education ( - : regression line). Data are presented as mean \pm SE for the 55 communities ( $\bullet$ : males; $\bigcirc$ : females); scores were normalised to mean 0 and variance 1 after factor analysis.

In mutually adjusted models, the climatic factor, nonsummer temperature, was associated with lifetime cumulative incidence of allergic rhinitis. The result was compatible with preliminary findings in asthma [18] and with another study in New Zealand [25]. One recent study concluded that mite allergen exposure is the most significant factor associated with asthma and allergic rhinitis in Taiwan [32]. Increased temperature (up to $30^{\circ} \mathrm{C}$ ) and relative humidity favour the development of mites, especially during colder seasons [37]. In a subtropical climate, indoor environmental factors, such as home dampness and mould growth, have been proved to be strong predictors of respiratory symptoms, including cough, wheezing, bronchitis, asthma and allergic rhinitis [38, 39]. No indoor temperature or relative humidity data were available in the present study, and only outdoor air monitoring data could be used in exposure assessment. Although the high outdoor humidity in Taiwan (monthly mean $68-80 \%$ ) is an important determinant of indoor humidity, no significant humidity factor associated with allergic rhinitis could be identified (table 5), which was inconsistent with the previous finding that asthma was more prevalent in communities with higher winter humidity [18]. One possible explanation that was considered was that both elevated winter temperature and humidity were associated with increased prevalence of allergic rhinitis, which would indicate dust mite growth. However, winter humidity might have reduced rhinitis symptoms and therefore negated the effect of winter humidity on mite survival. Various species of pollen should be also considered in the pathogenesis of asthma and allergic rhinitis [40]. Further studies are warranted to identify the causal relationship between various pollen species and distinct atopic diseases.

It is of worth to note the interactions between air pollutants and climatic factors. Summer warmth was associated with increased prevalence of allergic rhinitis; however, nonsummer warmth only showed positive but nonsignificant correlations. After mutual adjustment, the effects of summer warmth disappeared but those of nonsummer warmth emerged (table 5). Crude estimates of the association between climatic factors and allergic rhinitis could be biased by air pollution and lead to misleading interpretations.

Except for "wheezing" and "whistling in the chest", the association between traffic-related exposure and allergyrelated symptoms or atopic manifestations was less clear. In West Germany, KRÄMER et al. [17] found that outdoor levels of NOx were associated with symptoms of allergic rhinitis. Another study of identical cross-sectional design showed that high levels of $\mathrm{SO}_{2}$ and black smoke in East Germany were associated with a lower prevalence of asthma and allergic rhinitis than in West Germany [41]; however, the design did not investigate the role of motor-vehicle pollutants, which biased the results. Both studies suggested a positive correlation between the prevalence of self-reported symptoms of allergic rhinitis and self-reported motor-vehicle traffic exposure, after adjusting for personal risk factors. High traffic noise was also found to be positively associated with nasal symptoms [13, 14]. In Egypt, SAMIR et al. [42] used bloodcadmium level as a parameter of degree and proximity of exposure to air pollution; they found a significant causal relationship between air pollution and allergic rhinitis. In human exposure studies using either controlled chamber protocols or nasal provocation tests, significantly increased levels of mast cell tryptase and eosinophil cationic protein in nasal lavage fluid were found in subjects with a history of allergic rhinitis who had been exposed to $400 \mathrm{ppb} \mathrm{NO}$ for $6 \mathrm{~h}$ $[19,43]$. All these results suggest that exposure to heavy traffic might provoke an asthma attack or aggravate pre-existing allergic rhinitis. For this reason, NOx and $\mathrm{CO}$ might serve as indicators of motor-vehicle emission levels rather than as direct measures of the causal agent. The present study findings were compatible with the hypothesis that exposure to traffic-related pollutants might have caused changes in the susceptibility of children to allergens, and, therefore, might have contributed to the development of allergic rhinitis.

High traffic density has been inversely correlated with concentrations of $\mathrm{O}_{3}$ [44]. $\mathrm{O}_{3}$ was also negatively associated with traffic-related air pollutants (table 4). Since the air pollutants examined in the present study were related, it was virtually impossible to isolate the health effects caused by each one. However, using all air pollutants in the regression model, no significant result was found, which suggested collinear effects between each air pollutant (data not shown). In the individual pollutant regression analysis, $\mathrm{O}_{3}$ showed negative associations with the prevalence of allergic rhinitis. One rational explanation considered was that $\mathrm{O}_{3}$ was formed at some distance from emission sources and scavenged in the city centre by nitrogen monoxide from motor-vehicle exhaust [45]. This suggested the hypothesis that direct emissions from motor-vehicle traffic, which scavenge $\mathrm{O}_{3}$ and, therefore, negatively correlate with $\mathrm{O}_{3}$ levels, were more important determinants of allergic rhinitis than secondary air pollutants, such as $\mathrm{O}_{3}$. The present authors believe that the opposing effects of $\mathrm{CO} / \mathrm{NOx}$ and $\mathrm{O}_{3}$ were caused by the combination of a positive effect of $\mathrm{CO}$ and $\mathrm{NOx}$ on allergic rhinitis and a negative relationship between $\mathrm{CO} / \mathrm{NOx}$ and $\mathrm{O}_{3}$.

NOx have been proved to be acute respiratory irritants in animal and controlled human exposure studies [19, 43]. Although not known to be a respiratory irritant, $\mathrm{CO}$ is known to affect cardiovascular function. Whether the significant 
association between traffic-related air pollution and allergic rhinitis was directly related to $\mathrm{NOx}$ or $\mathrm{CO}$ from automobile exhaust or caused by other traffic-related pollutants not measured by the air-monitoring stations could not be determined in the present study. Other possible motor-vehicle emissions include fine and ultrafine particles (including various heavy metals) and a wide range of organic compounds. However, DOCKERY et al. [22] found that fine-particle concentrations were unassociated with respiratory symptoms in children in the 24-cities study. Epidemiological data concerning associations between respiratory illness and organic compounds are also limited. In a study of indoor inhalable flour dust, there was either weak or inconsistent evidence of associations with rhinitis or nasal irritant sensitivity [46]. No significant association was noted between lifetime allergic rhinitis prevalence and fossil fuel combustion related air pollutants, namely $\mathrm{SO}_{2}$ and PM10, which was compatible with the previous analysis in asthma [18].

Although personal-exposure data were lacking, the ecological exposure assessment had many advantages in the present study. The density of elementary and middle schools in Taiwan was very high, and almost all of the surveyed children attended schools within $1 \mathrm{~km}$ of their homes. Monitoring stations located near the schools were also likely to be near the students' homes, and thus provided good indicators of both school and home exposure. A preliminary German study suggested that outdoor $\mathrm{NO}_{2}$ level was a better predictor for atopic diseases determination than $\mathrm{NO}_{2}$ exposure at the personal level [17]. The present study also proves the validity of outdoor data on traffic-related air pollutants from airmonitoring stations as predictors of the prevalence of allergic rhinitis.

It was questioned whether any possible bias could exist in the study design. Heating and air conditioning were rare in Taiwanese classrooms in 1995/1996. Coal stoves were used in $<2 \%$ of homes in 1994 , but probably more in rural than urban areas [47]. The selection of the study population in close vicinity to the 55 air-monitoring station was not random. Compared to all middle-school students in Taiwan, the selected subjects were similar in sex ratio (50.4\% male) and age (mean 13.8 yrs) but parents of these students might have received more education, smoked less and complained more about air pollution problems. The prevalence of allergic rhinitis in the subpopulation was a little higher than that in the total population (data not shown); however, it is not thought that results from the correlation study comparing the effects of climatic factors and air pollutants in allergic rhinitis were biased. Ecological confounders such as urbanisation and socialisation could be present in the data analysis and there might be incomplete adjustment between community differences and residual confounding. However, more complete personal risk factor data were very difficult to obtain in such a large-scale survey. The investigators decided not to try to obtain more personal information, because it would have resulted in a lower participation rate and would have introduced greater bias into the study.

It is not thought that any important potential confounders were missed in the present analysis. Migration from one community to another could lead to misclassification of exposure. However, errors in exposure assessment were likely to be random, which would reduce the magnitude of association but not introduce positive bias into the associations. Children in urban and rural communities might not live in the same proximity to their schools. Children who lived further away from school were more likely to be exposed to more air pollutants due to spending more time in traffic. Since rural children tended to live further away from their schools and in areas with less traffic-related air pollution than did city children, this could have reduced the association between traffic-related pollutants and allergic rhinitis prevalence. The exposure information obtained from air monitoring stations was limited to the criteria air pollutants in 1994 and subsequent years. Using air pollution and meteorological data from 1994 in exposure assessment was rational when considering the latency period of allergic rhinitis. Bias could be introduced if differential changes in these exposure variables were found between communities. However, from monitoring data in later years, differential changes were not seen (data not shown).

In conclusion, parental reports of physician-diagnosed and questionnaire-determined allergic rhinitis in the present study were both highly correlated with traffic-related air pollutants (nitrogen oxides, carbon monoxide and ozone) but not other pollutants (particulate matter with a 50\% cut-off aerodynamic diameter of $10 \mu \mathrm{m}$ and sulphur dioxide). Negative and relatively weak correlations with allergic rhinitis were found for the secondary air pollutant ozone. Physician-diagnosed allergic rhinitis in both sexes was also shown to be associated with nonsummer (September-May) warmth, probably mediated through exposure to common allergens such as dust mites. Public health policy for reducing certain traffic-related air pollutants might be needed because of the rapidly increasing prevalence of allergic rhinitis.

\footnotetext{
Acknowledgements. The authors would like to thank all the field workers who supported data collection, school administrators and teachers, and especially parents and children who participated in the present survey.
}

\section{References}

1. Lundback B. Epidemiology of rhinitis and asthma. Clin Exp Allergy 1998; 28: Suppl. 2, 3-10.

2. Wright AL, Holberg CJ, Martinez FD, Halonen M, Morgan W, Taussig LM. Epidemiology of physician-diagnosed allergic rhinitis in childhood. Pediatrics 1994; 94: 895-901.

3. Nathan RA, Meltzer EO, Selner JC, Storms W. Prevalence of allergic rhinitis in the United States. J Allergy Clin Immunol 1997; 99: 808s-814s

4. Magnus P, Jaakkola JJK. Secular trends in the occurrence of asthma among children and young adults: critical appraisal of repeated cross sectional surveys. BMJ 1997; 314: 17951799.

5. Omran M, Russel G. Continuing increase in respiratory symptoms and atopy in Aberdeen schoolchildren. BMJ 1996; 312: 34-37.

6. Butland BK, Strachan DP, Lewis S, Bynner J, Butler N, Britton J. Investigation into the increase in hay fever and eczema at age 16 observed between the 1958 and 1970 British birth cohorts. BMJ 1997; 315: 717-721.

7. Wüthrich B, Schindler C, Leuenberger P, AckermannLiebrich U. Prevalence of atopy and pollinosis in the adult population of Switzerland (SAPALDIA study). Int Arch Allergy Immunol 1995; 106: 149-156.

8. Sullivan SD, Weiss KB. Assessing cost-effectiveness in asthma care: building an economic model to study the impact of alternative intervention strategies. Allergy 1993; 48: $146-152$.

9. Mygind N, Dahl R. Epidemiology of allergic rhinitis. Pediatr Allergy Immunol 1996; 7: 57-62.

10. Settipane GA, Chafee FH. Nasal polyps in asthma and rhinitis, a review of 6037 patients. J Allergy Clin Immunol 1977; 59: 17-21.

11. Aberg N, Sundell J, Eriksson B, Hesselmar B, Aberg B. Prevalence of allergic diseases in schoolchildren in relation to 
family history, upper respiratory infections, and residential characteristics. Allergy 1996; 51: 232-237.

12. Strachan DP. Hay fever, hygiene and household size. $B M J$ 1989; 299: 1259-1260.

13. Weiland SK, Mundt KA, Ruckmann A, Keil U. Selfreported wheezing and allergic rhinitis in children and traffic density on street of residence. Ann Epidemiol 1994; 4: 243247.

14. Duhme H, Weiland SK, Keil U, et al. The association between self-reported symptoms of asthma and allergic rhinitis and self-reported traffic density on street of residence in adolescents. Epidemiology 1996; 7: 578-582.

15. Ciccone G, Forastiere F, Agabiti N, et al. Road traffic and adverse respiratory effects in children. Occup Environ Med 1998; 55: 771-778.

16. de Marco R, Poli A, Ferrari M, et al. The impact of climate and traffic-related $\mathrm{NO}_{2}$ on the prevalence of asthma and allergic rhinitis in Italy. Clin Exp Allergy 2002; 32: 14051412.

17. Krämer U, Koch T, Ranft U, Ring J, Behrendt H. Trafficrelated air pollution is associated with atopy in children living in urban areas. Epidemiology 2000; 11: 64-70.

18. Guo YL, Lin YC, Sung FC, et al. Climate, traffic-related air pollutants and asthma prevalence in middle-school children in Taiwan. Environ Health Perspect 1999; 107: 1001-1006.

19. Wang JH, Devalia JL, Duddle JM, Hamilton SA, Davies RJ. Effect of six-hour exposure to nitrogen dioxide on earlyphase nasal response to allergen challenge in patients with a history of seasonal allergic rhinitis. J Allergy Clin Immunol 1995; 96: 669-676.

20. Diaz-Sanchez D, Penichet-Garcia M, Saxon A. Diesel exhaust particles directly induce activated mast cells to degranulate and increase histamine levels and symptom severity. J Allergy Clin Immunol 2000; 106: 1140-1146.

21. Wyler C, Braun-Fahrlander C, Kunzli N, et al. Exposure to motor vehicle traffic and allergic sensitization. Epidemiology 2000; 11: 450-456.

22. Dockery DW, Cunningham J, Damokosh AI, et al. Health effects of acid aerosols on North American children: respiratory symptoms. Environ Health Perspect 1996; 104: $500-505$.

23. Lecha Estela LB. Biometeorological classification of daily weather types for the humid tropics. Int J Biometeorol 1998; 42: 77-83.

24. Piccolo MC, Perillo GM, Ramon CG, Di Dio V. Outbreaks of asthma attacks and meteorologic parameters in Bahia Blanca, Argentina. Ann Allergy 1988; 60: 107-110.

25. Hales S, Lewis S, Slater T, Crane J, Pearce N. Prevalence of adult asthma symptoms in relation to climate in New Zealand. Environ Health Perspect 1998; 106: 607-610.

26. 41st World Medical Assembly. Declaration of Helsinki: recommendations guiding physicians in biomedical research involving human subjects. Bull Pan Am Health Organ 1990; 24: 606-609.

27. Kaiser HF. The varimax criterion for analytical rotation in factor analysis. Psychometrika 1958; 23: 187-200.

28. Dockery DW, Speizer FE, Stram DO, Ware JH, Spengler JD, Ferris BG Jr. Effects of inhalable particles on respiratory health of children. Am Rev Respir Dis 1989; 139: 587-594.

29. Ko YC. Air pollution and its health effects on residents in
Taiwanese communities. Kaohsiung J Med Sci 1996; 12: 657669.

30. Ng TP, Tan WC. Epidemiology of allergic rhinitis and its associated risk factors in Singapore. Int J Epidemiol 1994; 23 : 553-558.

31. Sly RM. Changing prevalence of allergic rhinitis and asthma. Ann Allergy Asthma Immunol 1999; 82: 233-248.

32. Li LF, Lin MC, Yang CT, et al. Comparison of indoor allergens, allergic scores, and demographic data in Taiwanese adults with asthma or allergic rhinitis, or both. $J$ Formos Med Assoc 1999; 98: 486-491.

33. Nicolai T, von Mutius E. Pollution and the development of allergy: the East and West Germany story. Arch Toxicol 1997; 19: 201s-206s.

34. Saraclar Y, Yigit S, Adalioglu G, Tuncer A, Tuncbilek E. Prevalence of allergic diseases and influencing factors in primary-school children in the Ankara Region of Turkey. J Asthma 1997; 34: 23-30.

35. Hjern A, Hedberg A, Haglund B, Rosen M. Does tobacco smoke prevent atopic disorders? A study of two generations of Swedish residents. Clin Exp Allergy 2001; 31: 908-914.

36. Basagaña X, Sunyer J, Zock JP, et al. Incidence of asthma and its determinants among adults in Spain. Am J Respir Crit Care Med 2001; 164: 1133-1137.

37. Arlian LG, Dippold JS. Development and fecundity of Dermatophagoides farinae (Acari: Pyroglyphidae). J Med Entomol 1996; 33: 257-260.

38. Yang CY, Chiu JF, Cheng MF, Lin MC. Effects of indoor environmental factors on respiratory health of children in a subtropical climate. Environ Res 1997; 75: 49-55.

39. Li CS, Hsu LY. Home dampness and childhood respiratory symptoms in a subtropical climate. Arch Environ Health 1996; 51: 42-46.

40. Bass DJ, Delpech V, Beard J, Bass P, Walls RS. Late summer and fall (March -May) pollen allergy and respiratory disease in northern New South Wales, Australia. Ann Allergy Asthma Immunol 2000; 85: 374-381.

41. von Mutius E, Martinez FD, Fritzsch C, Nicolai T, Roell G, Thiemann HH. Prevalence of asthma and atopy in two areas of West and East Germany. Am J Respir Crit Care Med 1994; 149: 358-364.

42. Samir M, Magdy S, el Fetoh AA. Air pollution in relation to allergic and nonallergic rhinitis. Arch Otolaryngol Head Neck Surg 1997; 123: 746-748.

43. Wang JH, Duddle J, Devalia JL, Davies RJ. Nitrogen dioxide increases eosinophil activation in the early-phase response to nasal allergen provocation. Int Arch Allergy Immunol 1995; 107: 103-105.

44. Wjst M, Reitmeir P, Dold S, et al. Road traffic and adverse effects on respiratory health in children. $B M J 1993 ; 307$ : 596-600.

45. Kleinman L, Lee YN, Springston SR, et al. Peroxy radical concentration and ozone formation rate at a rural site in the southeastern United States. J Geophys Res 1995; 100: 72637273.

46. Brisman J, Jarvholm B, Lillienberg L. Exposure-response relations for self reported asthma and rhinitis in bakers. Occup Environ Med 2000; 57: 335-340.

47. Chen PC, Lai YM, Wang JD, et al. Adverse effect of air pollution on respiratory health of primary school children in Taiwan. Environ Health Perspect 1998; 106: 331-335. 